\title{
Atribuições e dificuldades dos controladores internos municipais na região da Amcespar (PR)
}

O Controle Interno consagra-se como uma ferramenta pertinente para a melhoria da gestão pública. Suas atividades promovem o atendimento aos princípios constitucionais e orientam o gestor público sobre equívocos ocorridos nas atividades administrativas. Visando contribuir efetivamente à Administração Pública, este trabalho tem por objetivo identificar as principais atividades atributivas dos controladores internos de órgãos públicos municipais, da região da AMCESPAR, em frente ao hodierno panorama da Contabilidade Aplicada ao Setor Público, além de evidenciar as dificuldades encontradas no exercício de suas funções. Os procedimentos metodológicos aplicados são exclusivamente por meio do delineamento de levantamento de dados, possuindo cunho descritivo e utilizando abordagem quantitativa e qualitativa, onde aplicouse um questionário estruturado. Dos dez municípios pertencentes a amostra, obteve-se respostas de nove questionários. Os resultados obtidos sugerem que as principais atribuições dos controladores internos são a participação efetiva em audiências públicas, a verificação periódica de empenhos emitidos e pagamentos efetuados, a averiguação dos índices obrigatórios o acompanhamento e fiscalização da adequação da LOA quanto às diretrizes do PPA. As principais dificuldades encontradas sugerem a falta de apoio jurídico para subsidiar as decisões dos controladores; a carência de idealização prévia das atividades a serem realizadas pela Administração Pública; a ausência do estabelecimento de mecanismos que comprovem a gestão fiscal responsável, e a falta de integração entre os setores da Administração Pública.

Palavras-chave: Controle Interno; Gestão Pública; Atribuições e Dificuldades.

\section{Assignments and difficulties of municipal internal controllers of region Amcespar (PR)}

\begin{abstract}
The Internal Control has established itself as a relevant tool for improving public management. Its activities promote compliance with constitutional principles and guide public officers of mistakes occurred in administrative activities. To contribute effectively to the Public Administration, this study aims to identify the main attributive activities of internal controllers of municipal public agencies, region of AMCESPAR, opposite the present-day panorama of Applied Accounting Public Sector, besides highlighting the difficulties encountered in the exercise of its functions. The methodological procedures are applied exclusively through the data collection design, possessing descriptive nature, using quantitative and qualitative approach, which was applied a structured questionnaire. Of the ten municipalities in the sample, it obtained nine questionnaire responses. The results suggest that the main responsibilities of internal controllers are the effective participation in public hearings, periodic check issued and payments made commitments, to investigate the indices required monitoring and supervision of the adequacy of the LOA as the PPA guidelines. The main difficulties encountered suggest the lack of legal support to subsidize the decisions of controllers; the lack of prior idealization of activities to be carried out by the Public Administration; the absence of the establishment of mechanisms to prove the responsible fiscal management, and the lack of integration between sectors of Public Administration.
\end{abstract}

Keywords: Internal Control; Public Management; Assignments and Difficulties.

Topic: Gestão Pública

Reviewed anonymously in the process of blind peer.

Tiago Eloy da Luz

Universidade Federal do Paraná, Brasil

http://lattes.cnpq.br/1581287481693137

tiagomall_eloy@hotmail.com

Eduardo Aaron Clazer

eduardoclazer@hotmail.com

Flávio Ribeiro

Universidade Federal do Paraná, Brasil

http://lattes.cnpq.br/9438513814847904

flavioribeiro@irati.unicentro.br

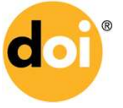

DOI: 10.6008/SPC2179-684X.2016.003.0011
Received: 12/06/2016

Approved: 14/11/2016

\section{Referencing this:}

LUZ, T. E.; CLAZER, E. A.; RIBEIRO, F.. Atribuições e dificuldades dos controladores internos municipais na região da Amcespar (PR). Revista Brasileira de Administração Científica, v.7, n.3, p.154-169, 2016. DOI: http://doi.org/10.6008/SPC2179-684X.2016.002.0011 


\section{INTRODUÇÃO}

As informações repassadas pelas entidades públicas à população, visando o processo de transparência e comprovação da efetividade da gestão pública, são compreendidas como a essência da Contabilidade Pública. A introdução da Lei Complementar (LC) no 101, no início do ano 2000, trouxe novos parâmetros à Contabilidade Aplicada ao Setor Público, principalmente no que se refere à transparência na gestão e divulgação da aplicação dos recursos públicos.

Também conhecida como Lei de Responsabilidade Fiscal (LRF), a LC 101/2000 foi implementada pelo Governo Federal na intenção de definir um novo critério de Administração Pública, a qual aborda que a mesma não deve realizar dispêndios maiores do que suas possibilidades, estimulando o Estado a ser mais eficiente na gestão de recursos públicos (GADELHA, 2012). 0 art. 74 da Constituição Federal (CF) determina que os poderes Legislativo, Executivo e Judiciário mantenham, de forma interligada, um sistema de controle interno com o intuito de diversas competências tornando a gestão pública mais transparente.

O controle interno assume um papel relevante no contexto das organizações públicas, pois é por meio dele, que os gestores estabelecem ações com o intuito de monitorar as atividades da entidade, a fim de assegurar que seus objetivos possam ser alcançados. No setor público, a implementação de um sistema de controle interno passou a ser obrigatória com o advento da Lei de Responsabilidade Fiscal (BEUREN; ZONATTO; 2014).

A integração entre as funções de trabalho do controle interno propicia a melhor adequação das contas públicas às normas legislativas vigentes e possibilita o cumprimento da eficiência, eficácia e economicidade na gestão dos recursos públicos (AMUDO, INANGA; 2009) além de detectar as irregularidades e garantir a efetividade da gestão. Sob a ótica de Buligon (2012), a ausência de controle interno nas organizações públicas implica na incapacidade da administração de mensurar o cumprimento das metas fixadas, tais como: Projetos/Programas Governamentais; Plano Plurianual; Lei de Diretrizes, bem como, da própria execução do orçamento, entre outras.

Diante das atuais exigências e máximo controle exercido pelo Tribunal de Contas, os controladores internos da esfera pública, devem atender às diversas necessidades desses órgãos fiscalizadores, propondo o cumprimento de suas funções e garantindo a obediência aos princípios da Administração Pública. Todavia, por desconhecimento à legislação ou por falta de estrutura física e/ou de pessoal, é possível que profissionais de controle interno não cumpram plenamente suas atribuições para com a Administração Pública. Tal descumprimento pode gerar danos à Administração, que pode sofrer sanções pelos órgãos fiscalizadores, ocasionando, por exemplo, a suspensão de transferências voluntárias da Federação, e aplicação de multas ao gestor. Nesse contexto, o presente estudo busca identificar as principais dificuldades encontradas no exercício das atividades atributivas dos controladores internos de órgãos públicos municipais, da região da AMCESPAR, estado do Paraná, frente ao hodierno panorama da Contabilidade Aplicada ao Setor Público. O estudo contribui para o entendimento de aspectos de controle interno público. Especificamente, quando se consideram os entes municipais, onde a literatura ainda é incipiente, o que apresenta uma possibilidade 
profícua de inserir esta temática na discussão teórica nessa área do conhecimento e, consequentemente, na verificação empírica entre os atores no campo do da contabilidade pública.

\section{REVISÃO TEÓRICA}

\section{Planejamento Público}

A atividade do planejamento é algo recente na história das organizações. Ela surge em decorrência das mudanças organizacionais e da crescente complexidade da sociedade. Seus objetivos visam a definição de metas, além de avaliar o desempenho organizacional, durante todo o processo de gestão (KOMINIS; DUBAU, 2012). A perspectiva de uma Administração Pública voltada, primeiramente, a eficaz utilização dos recursos advindos de receitas públicas e, voltada também, ao processo de transparência efetivo da utilização de tais recursos ao controle externo, sucede-se por meio da elaboração de instrumentos de planejamento financeiro, ou seja, um traçado de receitas e despesas que poderão ocorrer no período.

Na ótica de Quintana (2011), o planejamento é a primeira etapa em qualquer processo de gestão, seja na entidade pública ou na empresa privada, pois por meio dele serão traçados os desejos, as intenções, as expectativas, o futuro projetado para essa empresa ou entidade. Planejar, dentro da esfera pública, pressupõe o alcance de ações que não sejam contrárias à legislação e que objetivem anseios da população. Desse modo, toda e qualquer mudança nas leis de planejamento do setor público deve ser aprovada pela fiscalização a que o Poder Executivo está submetido, ou seja, pelo Poder Legislativo, esse, que tem a premissa de averiguar o comprometimento da Administração Pública perante os cidadãos.

Por meio da normatização da Lei Complementar no 101/2000, conhecida como Lei de Responsabilidade Fiscal (LRF) foi assegurado legislativamente o cumprimento do processo de transparência no setor público. Na referida esfera, a técnica da transparência está relacionada à utilização correta dos recursos públicos, obedecendo a legislação vigente e às normas impostas. A introdução da LRF no contexto da Contabilidade Pública provocou a obrigatoriedade dos quesitos transparência, controle e fiscalização dos recursos destinados aos serviços propostos ao bem comum, prestados por entidades do referido setor. Em suma, a transparência pública consiste na divulgação apropriada, disponibilizada em tempo real e/ou de acordo com os referidos prazos, ao Estado e à sociedade, de todas as medidas contábeis, administrativas e financeiras utilizadas para a variação do patrimônio público, perante a obtenção ou realização de serviços, programas e/ou atividades em prol do bem comum. Portanto, a LRF pressupõe uma atuação delineada e transparente, onde se previne o excesso de despesa, prevenindo riscos e o equilíbrio das contas do âmbito público, salientando uma gestão fiscal responsável.

A adoção do disposto pela LRF na esfera pública veio com o intento de estabelecer normas definitivas para a efetivação uma gestão fiscal com responsabilidade, conduzida pelos princípios da administração pública: legalidade, impessoalidade, moralidade, publicidade e eficiência. A Lei Complementar em si estabelece, em seu conjunto normativo, que o gestor público deve facilitar o acesso às informações de caráter público a todos quem possa interessar, por meio de publicações digitais no referido Portal de 
Transparência, demonstrações contábeis de clara compreensão, além de propor incentivo à participação da sociedade em audiências de elaboração orçamentária, prestação de contas e/ou debates de planos futuros, objetivando saciar informações ao controle externo.

O controle externo das entidades do setor público é realizado por órgãos alheios à estrutura do órgão público, que tem por finalidade a efetivação de instrumentos de verificação da eficácia das ações da gestão governamental. Bulgari (2014) entende que este controle tem natureza política, não havendo subordinação (hierarquia ou tutela) do Legislativo sobre o Executivo. O controle interno visa a prevenção de erros, fraudes e precipitações no campo das finanças públicas. Apresenta-se como uma ferramenta essencial para a elaboração verídica das variações patrimoniais do setor público. Sua relevância no procedimento da transparência pública é definitiva, competindo, então, à uma participação ativa nesse processo.

Ao ser introduzida no contexto das finanças públicas, a LRF trouxe novas orientações no sentido da transparência das contas públicas. Essa Lei Complementar, estabeleceu a motivação inicial para o setor público proporcionar o cumprimento da legislação, visando a isenção das sanções determinadas pelas normas promulgadas, e ao pleno conhecimento da situação administrativa pela sociedade.

\section{Controle Interno Municipal}

O órgão de controladoria, nas entidades privadas podem ser descritos como um conjunto de conhecimentos que se constituem em bases teóricas e conceituais de ordens operacional, econômica, financeira e patrimonial, relativas ao controle do processo de gestão organizacional (BORINELLI, 2006). A controladoria consagra-se, também, na visão de Schmidt, Santos e Martins (2014) como um novo ramo do conhecimento da gestão empresarial. Visando atender o suporte de informações aos gestores e aos usuários externos, a controladoria dedica-se a gerar informações fidedignas e eficazes, auxiliando o processo de tomada de decisões das atividades empresariais.

O controle interno, nas repartições públicas, segundo o definido pela normativa da American Institute of Certified Public Accountants (AICPA) compreende o plano de organização e todos os métodos e medidas, adotadas numa empresa para proteger seu ativo, verificar a exatidão e a fidedignidade de seus dados contábeis, incrementar a eficiência operacional e promover a obediência às diretrizes administrativas estabelecidas (AICPA, citado por CASTRO, 2013).

$\mathrm{Na}$ ótica de Souza, et. al. (2007) o controle interno faz parte dos planos das organizações integrando a administração, configurando-se como o ponto central do plano organizacional de qualquer entidade organizada, com o compromisso principal de auxiliar a administração diante de seus objetivos. Nesse contexto, o controle interno municipal, portanto, tem a função de verificar e orientar os movimentos gerados diante da veracidade das informações prestadas pelo aumento ou diminuição do patrimônio público (MARTIN, SANDERS, SCALAN; 2014). A atividade principal do controle interno se aplica a quaisquer casos de utilização de recursos públicos, que venham a modificar a estrutura patrimonial de cada poder constitucional.

Por ser parte integrante da Administração Pública, o sistema de controle interno tem como referencial os princípios constitucionais instituídos na área do Direito Administrativo, sendo eles: princípio 
da Publicidade, Legalidade, Moralidade e Impessoalidade. Os mesmos fazem parte do trabalho diário desse sistema, e contribuem para a qualidade e veracidade das informações apresentadas. Além dos princípios administrativos já comentados, Bulgari (2014) salienta que o sistema de controle interno dispõe de três princípios necessários para nortear suas atividades diárias, sendo eles: Eficiência; Eficácia e; Economicidade.

Bulgari (2014) complementa que a eficiência está relacionada à utilização racional dos recursos; é apresentar um desempenho satisfatório sem desperdício. A eficácia, por sua vez, é a capacidade de realizar as coisas e alcançar objetivos e metas pré-determinados. O autor supracitado completa que uma ação é econômica quando proporciona a aquisição de insumos ou a contratação de serviços ao menor preço, sem prejuízo da qualidade. No setor público, a qualidade do serviço a ser realizado é essencial para o bem comum da população, portanto, é ideal a união entre economia e qualidade, para a excelência do processo de despesa do setor público (BROWN; POTT; WÖMPENER, 2014; MARTIN; SANDERS; SCALAN, 2014)

Tais princípios são as orientações para a realização do trabalho do responsável pelo controle interno municipal. A importância do cumprimento dos princípios descritos, propicia ao controlador interno um trabalho mais efetivo, que influenciam no cumprimento das normas e na gestão pública mais eficiente quanto à utilização dos recursos

Como toda ferramenta gerencial, o controle interno tem diversos objetivos a serem planejados e executados durante o exercício, perante a verificação de atos públicos diários que visam o cumprimento de normativas expressas na Constituição Federal (CF) e Lei de Responsabilidade Fiscal (LRF), principalmente quanto ao processo de utilização dos recursos públicos e procedimentos de transparência de tais movimentações. Compete, portanto, ao controle interno a observância dos princípios da Administração Pública, onde a mesma é a principal interessada na fidedignidade da efetivação apropriada de uma gestão pública correta.

\section{METODOLOGIA}

A pesquisa apresenta característica descritiva, com abordagem qualitativa. Trata-se, quanto aos procedimentos, de um estudo de levantamento e documental. A amostra restringe-se aos municípios que compõem a Associação dos Municípios do Centro-Sul do Estado do Paraná (AMCESPAR) no total de 10 municípios paranaenses. A amostragem deu-se de forma não probabilística e intencional. Dos municípios que representam a amostra inicial do estudo, obteve $90 \%$ de respostas. A coleta de dados realizou-se por meio de levantamento de dados enviados à amostra da pesquisa, com a utilização de um questionário estruturado, objetivando a identificação da problemática evidenciada. Para subsidiar a análise das respostas obtidas, utilizou-se de material bibliográfico publicado, e da pesquisa documental, observando normativas que estabelecem as atividades a serem executadas pelos controladores municipais.

O instrumento utilizado para o desenvolvimento dessa pesquisa foi um questionário estruturado, adaptado da pesquisa de Buligon (2012). O período de envio do questionário e recebimento de respostas foi durante o mês de outubro do ano de 2015 . O presente instrumento de coleta de dados dispõe de 20 questões 
objetivas, e possui o propósito de identificar as atividades atributivas mais exercidas pelos respondentes, além de evidenciar as atividades apontadas como menos relevantes na execução de suas funções.

Tal instrumento de coleta de dados, utilizou a escala de Likert como ferramenta de medida e mensuração das respostas às questões apresentadas. A escala de Likert utilizada como ferramenta de coleta das respostas estabeleceu três níveis de respostas para as perguntas apresentadas no questionário, a saber: "Sempre", "Regularmente" e "Nunca". Para a análise dos dados, as questões foram separadas de acordo com sua característica funcional principal, listada a seguir: (I) Fiscalização e elaboração de relatórios; (II) Planejamento e Execução Orçamentária, e; (III) Suporte para correção de erros e prestação de contas. Tais características funcionais foram determinadas pelos autores, com adaptação dos estudos de Castro (2013), Callado (2013) e Buligon (2012); ambos estendendo o conhecimento bibliográfico sobre a relevância do controle interno para a esfera pública.

Por fim, a análise quantitativa ocorreu por meio do emprego de técnicas da estatística descritiva, tais como frequência de respostas, com o subsídio do Microsoft Office Exce ${ }^{\circledast}$. A interpretação dos dados ocorreu com o auxílio da evidenciação por meio da frequência de respostas do questionário, correlacionando a literatura existente com a prática evidenciada nas respostas obtidas, sendo verificadas as principais atividades atributivas dos controladores municipais respondentes, e evidenciar as atividades apontadas como menos relevantes, respondendo a problemática apresentada.

\section{RESULTADOS E DISCUSSÃO}

Conforme o objetivo proposto e os procedimentos metodológicos aplicados na pesquisa, obteve-se a resposta efetiva de 9 controladores municipais da amostra estabelecida. Todas as perguntas do questionário aplicado foram respondidas de modo efetivo, proporcionando um entendimento sobre as principais atribuições dos controladores internos municipais e as atividades que podem sem apontadas como dificuldades na execução de suas tarefas. A Tabela 1 apresenta os resultados obtidos quanto às características funcionais de fiscalização e elaboração de relatórios.

Tabela 1: Atividades quanto às características de fiscalização e elaboração de relatórios.

\begin{tabular}{|c|c|c|c|c|}
\hline \multirow{2}{*}{ QUESTÕES } & \multicolumn{4}{|c|}{ FREQUÊNCIA DE RESPOSTAS (\%) } \\
\hline & SEMPRE & REGULARMENTE & NUNCA & TOTAL \\
\hline $\begin{array}{l}\text { Recebe/solicita documentações de outros setores da } \\
\text { Administração Pública para análise prévia? }\end{array}$ & 11 & 89 & - & 100 \\
\hline $\begin{array}{l}\text { Há fiscalização e controle quanto aos índices de } \\
\text { despesa com pessoal, despesas com Saúde e } \\
\text { Educação estabelecidos pela legislação? }\end{array}$ & 78 & 22 & - & 100 \\
\hline $\begin{array}{l}\text { Realiza a fiscalização do cumprimento financeiro de } \\
\text { convênios assinados e repassados? }\end{array}$ & 33 & 45 & 22 & 100 \\
\hline $\begin{array}{l}\text { Verifica a veracidade da prestação de contas de } \\
\text { auxílios e subvenções repassadas às outras } \\
\text { entidades? }\end{array}$ & 44,5 & 55,5 & -- & 100 \\
\hline $\begin{array}{l}\text { Quando há uma despesa sem que esteja planejada } \\
\text { nas leis orçamentárias, há a procura do controle } \\
\text { interno para averiguação da situação? }\end{array}$ & - & 67 & 33 & 100 \\
\hline $\begin{array}{l}\text { A periodicidade em que as informações do Controle } \\
\text { Interno são obtidas, encaminhadas e/ou } \\
\text { apresentadas ao Gestor Municipal: }\end{array}$ & 78 & 22 & - & 100 \\
\hline
\end{tabular}


Emite relatórios próprios no intuito de validar informações de índices obrigatórios (Educação/Saúde/Pessoal/etc.)?
33
67

As questões do Tabela 1 estabelecem diretrizes às atividades fiscalização e elaboração de relatórios que devem ser executadas pelos controladores internos municipais no âmbito de seu exercício profissional. O desenvolvimento da análise do referido Tabela, é apresentado a seguir.

Solicitar e/ou receber documentações dos órgãos da Administração Pública para fiscalização e análise prévia, estabelece mecanismos de garantia à entidade pública. Por meio das análises prévias, o Controle Interno determina sugestões, e ou alterações nas práticas administrativas dos setores envolvidos. Observa-se que o ato de solicitar ou receber documentação desses órgãos é executado regularmente por $89 \%$ dos respondentes. $11 \%$ afirmam que solicita sempre esse tipo de documentação para análise prévia. Observa-se que as respostas obtidas vão de encontro ao que se espera para práticas de controle.

De acordo com o exposto na legislação, o controle interno deve acompanhar o cumprimento dos limites de gastos do Poder Executivo Municipal. Nesse contexto, deve haver fiscalização quanto ao cumprimento do limite de gastos com pessoal, e às despesas vinculadas das áreas de Saúde e Educação. Verifica-se que $78 \%$ dos respondentes executam sempre a fiscalização e controle quanto aos índices descritos, exercendo sua atribuição. Já outros $22 \%$ afirmam que regularmente controlam esses índices, sugerindo, dessa proporção das respostas, um descumprimento da legislação. Quanto do ato de prestação de contas municipal, o relatório do controle interno solicita um parecer sobre a realização da fiscalização dos convênios e subvenções concedidas à outras entidades. Conforme demonstrado, $22 \%$ dos controladores assinalaram que nunca realizam essa fiscalização, sugerindo descumprimento à legislação estadual, possibilitando falhas na accountability municipal.

O controlador interno deve acompanhar e fiscalizar as subvenções repassadas. Visando a prática do bom gasto público e a legislação vigente, deve-se solicitar e acompanhar a fidedignidade da prestação de contas desses repasses. Nesse contexto, o controle interno deve fiscalizar se houve bom uso dos recursos públicos repassados, e acompanhar a periodicidade das prestações de contas dessas entidades. Constata-se que aproximadamente $56 \%$ dos respondentes regularmente verificam a fidedignidade das prestações de contas de subvenções repassadas pela entidade pública municipal. Apenas $44 \%$ dos respondentes verificam sempre a prestação de contas das subvenções repassadas, a fim de averiguar se o recurso público dispendido na subvenção foi bem aplicado.

Para todo e qualquer ato que seja necessária a utilização de recursos públicos, deve-se, primeiramente, haver planejamento de tal ação, e elencá-la nas leis orçamentárias. Em pequenos municípios, pode ocorrer o não planejamento de determinadas atividades, e são frequentes as mudanças nas leis orçamentárias. Objetivando o cumprimento da legislação, o controlador interno deve sempre verificar, juntamente aos setores responsáveis da Administração Pública, eventual interesse de realização de despesa que não esteja planejada, ou até mesmo sua realização sem observância dos obrigatórios estágios de execução de despesas. Quando trata-se de procura do controle interno, pelos responsáveis das pastas 
administrativas, a maior proporção de respondentes, $67 \%$, ressalta que regularmente há desempenho dessa ação, ou seja, regulamente os responsáveis pelos setores da Administração Pública procuram o controlador interno para averiguação da situação descrita. Corroborando, outros 33\% afirmam que tais responsáveis nunca solicitam a opinião dos controladores internos, para verificação da situação orçamentária.

Observa-se que parte dos respondentes afirma indiretamente que apesar de saber da existência de prestações de serviços e/ou aquisições de mercadorias em descumprimento ao art. 60 da Lei no 4.320/1964 (que veda a realização de despesa sem prévio empenho), foram sinceros ao afirmar que não são notificados sobre o fato. Evidencia-se, que caso o fosse, necessitaria adotar medidas cabíveis para apuração das irregularidades.

A existência do trabalho de controle de nada adiantaria se não fosse reportado, as incorreções ocorridas nos atos da administração, para suas devidas correções. Nesse sentido, é de fundamental relevância o encaminhamento de equívocos ao gestor público, visando expurgação dos erros. Visando uma gestão responsável é essencial o fornecimento de informações sobre a fiscalização e controle ocorrido ao gestor público. Por meio dessas informações são analisadas as atividades e discutidas as dificuldades encontradas, objetivando a confrontação de soluções, para resolvê-las. Constata-se, na Tabela 1, que a maior proporção dos respondentes, $78 \%$, afirmam que sempre encaminham e apresentam as informações obtidas ao gestor municipal. Entretanto, outros $22 \%$ afirmam que regularmente enviam tais informações.

Tem-se ciência que a obrigatoriedade de investir $15 \%$ da receita de impostos e transferências intergovernamentais de impostos na área da Saúde, e 25\% na Educação é exigência constitucional. Dessa forma, fica a cargo do controlador interno, verificar a evolução dos índices, por meio da emissão de relatórios próprios, haja vista seu presumido conhecimento técnico envolvido, ou apenas (e erroneamente) se utilizar de todos os relatórios contábeis que lhe são fornecidos. No que concerne a questão da Tabela 1, a maior frequência observada à resposta da última pergunta, $67 \%$ dos respondentes ressaltam que regularmente há emissão de relatórios próprios para validar informações de índices. Apenas 33\% dos respondentes afirmam que sempre emitem relatórios para averiguar tais informações. De qualquer forma, o que percebe-se na amostra da pesquisa é que não há entidade com controladoria interna que não busque a importante característica qualitativa da informação contábil denominada verificabilidade (estabelecida na NBC T 16.5). A Tabela 2, por sua vez, apresenta os resultados obtidos quanto às características funcionais de planejamento e execução orçamentária.

Tabela 2: Atividades quanto às características funcionais de planejamento e execução orçamentária.

\begin{tabular}{l|c|c|c|c}
\multicolumn{1}{c|}{ QUESTÕES } & \multicolumn{3}{c}{ FREQUÊNCIA DE RESPOSTAS (\%) } \\
\cline { 2 - 5 } & SEMPRE & REGULARMENTE & NUNCA & TOTAL \\
\hline $\begin{array}{l}\text { Com que frequência auxilia o setor de Contabilidade } \\
\text { quanto à programação orçamentária para as } \\
\text { diversas secretarias do Poder Executivo? }\end{array}$ & 45 & 33 & 22 & 100 \\
\hline $\begin{array}{l}\text { Os demais setores da Administração Pública } \\
\text { solicitam o parecer do setor do Controle Interno } \\
\text { para todo e qualquer ato que venha a utilizar os } \\
\text { recursos públicos? }\end{array}$ & 11 & 44,5 & 44,5 & 100 \\
\hline $\begin{array}{l}\text { Acompanha a execução dos objetivos e metas } \\
\text { definidos no PPA e da LDO? }\end{array}$ & 44,5 & 55,5 & - & 100 \\
\hline
\end{tabular}




\begin{tabular}{l|c|c|c}
\hline $\begin{array}{l}\text { Verifica a adequação da LOA com as diretrizes e } \\
\text { ações definidas na LDO e no PPA? }\end{array}$ & 55,5 & 44,5 & - \\
\hline $\begin{array}{l}\text { Fiscaliza os empenhos emitidos, e os pagamentos } \\
\text { realizados com que frequência? }\end{array}$ & 89 & 11 & - \\
\hline
\end{tabular}

Os pontos apresentados na Tabela 2 estabelecem orientações às atividades de planejamento e execução do orçamento, que devem ser controladas pelos profissionais controladores. Nesse sentido, a edificação da análise da referida tabela, é exposta a seguir.

Auxiliar na programação orçamentária dos órgãos da Administração Pública, corrobora ao controlador interno seu objetivo de comprovar a legalidade dos atos da gestão, nesse caso, da gestão orçamentária. Portanto, a participação do Controle Interno nessa etapa do planejamento orçamentário pode trazer bons resultados à Administração Pública. Vale ressaltar que a programação orçamentária e financeira deve ser elaborada após a publicação da Lei Orçamentária Anual, realizando eventuais acompanhamentos para correções de alterações no planejamento. Observa-se nos resultados da Tabela 2, que 45\% dos respondentes afirmam que sempre auxiliam na programação orçamentária dos setores da Administração Pública. Já outros 33\% dos respondentes dizem que regulamente auxiliam nessa atividade. E 22\% salientam que nunca ajudam na programação orçamentária dos setores da Administração Pública.

A solicitação de parecer do controlador interno, quando da execução de qualquer despesa que venha a utilizar recursos públicos, é muito relevante. Desde atos relativos ao processo de planejamento, execução orçamentária, apuração de limites mínimos e máximos, bem como mecanismos de prestação de contas, podem contar com auxílio da unidade de controladoria interna, que em muito pode colaborar com os diversos setores da administração. Não solicitar um parecer do responsável pelo controle interno pode causar problemas futuros, quando da prestação de contas municipal. Evidentemente, nem todo ato desempenhado necessita de parecer específico, como, por exemplo, alteração orçamentária pleiteada junto ao Poder Legislativo ou realizada em face de prévia autorização. Entretanto, diversos outros procedimentos, como, por exemplo, notificação de irregularidades, carecem de posicionamento do (a) profissional de controle interno. Observa-se que entre os municípios estudados, há tanto entidade na qual a controladoria avaliza todos os atos praticados (podendo incorrer até mesmo em excessos que podem sobrecarregar o profissional) quanto entidades em que nunca há posicionamento formal (podendo impactar negativamente no dia a dia da entidade, bem como na não utilização da ferramenta de controle exigida pela legislação pública aplicável).

No tocante à essa problematização, percebe-se que $44,5 \%$ dos respondentes informam que regularmente os demais setores da Administração Pública solicitam parecer do controle interno para as atividades a serem executadas. Outros $44,5 \%$, informam que nunca é solicitado qualquer parecer. E apenas 11\% dos respondentes corroboram à participação ativa dos setores da Administração, ao solicitarem sempre pareceres para todo e qualquer ato que venha a utilizar recursos públicos. Nesse contexto, sugere-se uma desvalorização das funções do controlador interno, perante os demais setores, sendo que os próprios respondentes percebem que tem sua função subestimada pelas secretarias. 
Salienta-se que acompanhar as metas e objetivos estabelecidos no PPA e LDO, também é uma atividade exigida pela Constituição Federal e pela LRF. Dessa maneira, o controle quanto à execução do PPA e da LDO deve ser feito de maneira integrada, respeitando as dizeres da legislação vigente à esfera pública. Apura-se que $44 \%$ dos controladores respondentes informaram que sempre realizam o acompanhamento da execução dos objetivos e metas definidos no PPA e na LDO. Todavia, 56\% dos respondentes disseram que regularmente acompanham tais fatores, sugerindo outro desrespeito à legislação em vigor.

Pensando na execução do orçamento, outra atividade que deve ser considerada relevante é o ato de verificar a adequação da LOA com as diretrizes e ações definidas na LDO e PPA. Essa atribuição oferece maior segurança à execução orçamentária da entidade pública quanto à legalidade dos dispêndios realizados. De acordo com o respaldado pela legislação, o controle interno deve acompanhar a execução dos objetivos e metas do PPA e LDO. Portanto, verificar se a LOA está de acordo com o que se pretende com as outras leis orçamentárias, previne qualquer tipo de gasto que não esteja planejado. Verifica-se que uns percentuais de $56 \%$ dos respondentes informaram que sempre verificam tal adequação. Já os demais $44 \%$ afirmam que regularmente realizam tal ação. Destaca-se a relevância da verificação de adequação entre as leis orçamentárias, pois se a mesma não é realizada pelo controlador, ou pela secretaria específica, será fiscalizada pelo Tribunal de Contas e/ou controle externo.

A fiscalização de notas de empenho e dos pagamentos efetuados similarmente proporciona à entidade pública, maior garantia de veracidade pelos seus atos executados. O controle interno, como fiscalizador do patrimônio da entidade do âmbito municipal deve estar atento à realização correta do empenho, e à baixa adequada dos dispêndios pagos. Percebe-se, na Tabela 2, que $89 \%$ dos respondentes verificam sempre a emissão dos empenhos e dos pagamentos realizados. Fato que merece ser destacado é que há entidade na região da AMCESPAR que afirmou nunca fiscalizar os supracitados estágios de execução da despesa. Tal ponto é, no mínimo, contraditório, até mesmo porque, anualmente, todos os controladores internos do Estado do Paraná emitem parecer específico que segue ao Tribunal de Contas no qual consta item específico de observação de tais procedimentos. Aparentemente, o (a) controlador (a) respondente descumpre uma de suas atribuições básicas, apesar de declarar que concorda com a realização dos processos realizados em cada período, quando da emissão de seu parecer. Neste caso ocorre afirmação sem embasamento ao órgão de controle por ignorância ou então intencionalmente. A Tabela 3 demonstra os resultados obtidos quanto às características funcionais de suporte para correção de erros e prestação de contas municipais.

Tabela 3: Atividades quanto às características funcionais de suporte de erros e prestação de contas.

\begin{tabular}{l|c|c|c|c}
\multicolumn{1}{c|}{ QUESTÕES } & \multicolumn{3}{c}{ FREQUÊNCIA DE RESPOSTAS (\%) } \\
\cline { 2 - 5 } & SEMPRE & REGULARMENTE & NUNCA & TOTAL \\
\hline $\begin{array}{l}\text { Ao ser encontrado erros, ou equívocos, na } \\
\text { documentação dos setores do Poder Executivo, }\end{array}$ & 67 & 33 & - & \\
$\begin{array}{l}\text { Controlador Interno expõe tais irregularidades ao } \\
\text { Prefeito, Secretários e funcionários públicos? }\end{array}$ & & & & \\
\hline $\begin{array}{l}\text { Há suporte jurídico que atenda às necessidades e } \\
\text { dúvidas que venham a surgir no meio da execução } \\
\text { de seu trabalho? }\end{array}$ & 11 & 67 & 22 & 100 \\
\hline
\end{tabular}




\begin{tabular}{|c|c|c|c|c|}
\hline $\begin{array}{l}\text { Há idealização prévia de atividades a serem } \\
\text { executadas pelos setores da Administração Pública? }\end{array}$ & 11 & 89 & - & 100 \\
\hline $\begin{array}{l}\text { Promove a integração operacional para o } \\
\text { desenvolvimento das atividades entre as Secretarias } \\
\text { Municipais e demais órgãos da Administração Direta } \\
\text { e Indireta do município? }\end{array}$ & 11 & 44,5 & 44,5 & 100 \\
\hline $\begin{array}{l}\text { Estabelece mecanismos voltados a comprovar a } \\
\text { eficácia, eficiência e a economicidade na gestão } \\
\text { orçamentária, financeira e patrimonial da } \\
\text { Administração Pública Municipal? }\end{array}$ & - & 67 & 33 & 100 \\
\hline $\begin{array}{l}\text { Participa ativamente de audiências públicas e } \\
\text { reuniões dos Conselhos de acompanhamento de } \\
\text { gastos nas áreas da Educação e Saúde? }\end{array}$ & 56 & 33 & 11 & 100 \\
\hline $\begin{array}{l}\text { Verifica o cumprimento das metas contidas no PPA, } \\
\text { resguardando documentação comprobatória para } \\
\text { prestação de contas? }\end{array}$ & 22 & 67 & 11 & 100 \\
\hline $\begin{array}{l}\text { Participa na elaboração do RREO e/ou do RGF } \\
\text { elaborado pelo departamento de contabilidade? }\end{array}$ & 22 & 67 & 11 & 100 \\
\hline
\end{tabular}

As indagações expostas no Tabela 3 fornecem parâmetros às atividades de correções de erros e prestação de contas, que devem ser executadas por controladores municipais. Dessa forma, a construção da análise desta tabela, é apresentada a seguir.

A divulgação de erros ou equívocos na documentação da entidade pública, aos responsáveis legais, é um quesito de grande relevância para o andamento das atividades na esfera pública. O controle interno deve expor, sempre que necessário, ao gestor e ordenadores de despesas os equívocos cometidos, para as correções necessárias, objetivando a não ocorrência futura do mesmo fato. A visão dos respondentes sobre a questão apresentada sugere que $67 \%$ dos respondentes sempre expõem os erros e/ou equívocos encontrados. Os outros 33\% sugerem que ao ser encontradas tais incorreções, regularmente expõem ao gestor, ou responsáveis. Destaca-se a resposta de 33\% dos respondentes que afirmaram que regularmente realizam a exposição das irregularidades encontradas no âmbito de seu controle. Propõe-se que como não expõem tais irregularidades com maior frequência, em algumas das vezes eles omitem tais informações, podendo ocasionar falhas à efetividade da gestão pública.

O suporte jurídico é essencial ao controlador interno, devido ao vasto conhecimento quanto à legislação vigente e quanto às sanções que podem ser aplicadas na esfera pública possuírem relevância na execução de sua profissão. A procuradoria jurídica fornece informações proeminentes, visando às práticas administrativas de acordo com o estabelecido pela legislação em vigor. O Tabela 3 demonstra que apenas $11 \%$ dos respondentes possui suporte jurídico que atenda às necessidades de seu trabalho. Observa-se que $67 \%$ da amostra assinalaram que regularmente possuem suporte jurídico, sugerindo que tal suporte é insuficiente para a realização de suas atividades; e outros $22 \%$ nem sequer possuem suporte jurídico. Propõese que caso haja ocorrência de desconhecimento de determinado tema ou necessidade de consultas específicas, o controlador interno pode estar suscetível a erros na execução de suas funções. O trabalho no setor de controladoria exige o monitoramento das atividades da Administração Pública, entretanto sem apoio jurídico efetivo, podem ocorrer equívocos que, futuramente, podem tornar-se erros não corrigidos.

Idealizar previamente as atividades que irão ser executadas pela Administração Pública está estabelecido na legislação, e deve ser demonstrada nas leis orçamentárias, tanto no PPA, quanto na LDO. No 
entanto, em prefeituras de pequenos municípios essa idealização prévia não é executada totalmente. Percebe-se, que $89 \%$ dos respondentes assinalaram que regularmente há idealização prévia das atividades a serem executadas, comprovando a assertiva anterior, e apenas $11 \%$ das respostas, assinalou que sempre há idealização prévia. Sugere-se, portanto, que não é executado efetivamente o planejamento nas entidades, o que pode prejudicar o controle a ser exercido na administração. A dificuldade de exercer um planejamento sugere um controle mais complexo e intenso nas atividades da esfera pública, visto que sem idealização prévia de gastos não se tem um estabelecimento concreto das metas a serem materializadas, e controlar as atividades sem planejamento prévio, torna-se mais difícil.

A integração operacional entre as secretarias da Administração Pública pressupõe o processo conjunto, visando desenvolver atividades ao bem comum. Nesse contexto, o controle interno tem muita pertinência, visto que esse órgão analisa e avalia a integração entre as secretarias administrativas. Verificase, que $44,5 \%$ dos respondentes assinalaram que regularmente promovem tal integração operacional, e outros $44,5 \%$ que nunca promoveram. Apenas um respondente assinalou que promove a integração operacional entre os setores da Administração Pública. Percebe-se a existência de falhas na integração operacional das entidades públicas municipais analisadas. Tal integração promove uma melhor prestação de serviços à comunidade e sua não existência, pode acarretar imperfeições ao realizar serviços voltados ao bem comum.

Outra atribuição para suporte de erros administrativos é o ato de comprovar a eficiência, eficácia e economicidade da gestão. Tal prática é, igualmente, um princípio do Controle Interno. Nesse sentido, o Controle Interno deve estar sempre atento aos gastos da Administração e se a efetividade do dispêndio realizado manterá as necessidades da população. Percebe-se, também no Tabela 3, que 67\% dos respondentes dizem que regularmente estabelecem mecanismos que comprovem a situação eficaz, eficiente e econômica da Administração Pública. Outros 33\% ressaltam que nunca realizam essa atividade. Sugere-se, com a percepção dos respondentes sobre a questão analisada, um descumprimento aos princípios do Controle Interno. Nenhuma resposta afirmou que estabelece mecanismos voltados a comprovar a eficiência, eficácia e economicidade da gestão pública, propondo que os ideais do referido órgão não são paralelos à legislação. Zelar pelo cumprimento e efetivação dos princípios de eficiência, eficácia e economicidade, propicia à Administração Pública, maior excelência no processo de despesa do setor público. Nesse contexto, o estabelecimento de mecanismos que promovam tais princípios dentro da administração, são de relevante valor às ações públicas.

Voltando às atividades práticas de prestação de contas, a participação em audiências e reuniões fortalece a prática transparente da entidade pública. Nesse contexto, é atribuição do controlador interno municipal participar ativamente dessas atividades, fortalecendo o vínculo da entidade com o controle externo. A Tabela 3, expõe que $56 \%$ dos respondentes participam ativamente das atividades que visem a prática transparente ao controle externo, tais como audiências públicas e reuniões de conselhos. Os outros $33 \%$ dos respondentes, evadem-se dessa prática, ao responderem que regularmente participam dessa atividade. Já os $11 \%$ restantes esquivam-se dessa atribuição, informando que nunca participam das 
audiências destinadas à transparência pública. A pertinência da participação nas audiências públicas sugere maior transparência das contas do Poder Executivo, além de proporcionar à população plena participação no planejamento de atividades de cunho coletivo. Nesse sentido, percebe-se que em um município não há participação do controle interno nas audiências, propondo a não efetividade do controle quanto ao acompanhamento desta importante etapa da transparência municipal.

Corroborando, o resguardo da documentação que comprove o atingimento das metas estabelecidas no PPA é outra característica a qual o controlador interno deve estar atento. Ao planejar as atividades a serem executadas pela gestão, o controlador, além de verificar se tais metas foram alcançadas, deve possuir documentação que comprove a legalidade dos atos, para futuras prestações de contas. Nesse sentido, verifica-se que $67 \%$ dos respondentes praticam regularmente a atividade descrita. Apenas $22 \%$ assinalaram que sempre verificam as metas do PPA, e resguardam documentação comprobatória. Ressalva-se que, apenas 1 respondente informou que nunca guarda documentação comprobatória. Sugere-se, portanto, que essa controladoria não possui documentos relevantes para a comprovação da utilização do dinheiro público, pois não possui dados comprobatórios que visam o atendimento à essa necessidade.

O cumprimento das metas estabelecidas nas leis orçamentárias elaboradas pelo setor público é de fundamental pertinência. Ademais, o Poder Legislativo e o Tribunal de Contas realizam a verificação do cumprimento dessas metas. Nesse contexto, resguardar a documentação que comprove a realização das metas definidas no PPA é essencial para a confirmação da eficaz aplicação dos recursos públicos, e para possível verificação dos órgãos fiscalizadores.

O Relatório Resumido da Execução Orçamentária (RREO) e o Relatório de Gestão Fiscal (RGF) fornecem informações sobre a execução do orçamento e sobre índices de gestão de determinado período. A participação do controle interno, nessa atividade, sugere maior segurança na fidedignidade dos dados divulgados, ao controle externo, tanto é que os demonstrativos integrantes do RGF são assinados pela controladoria interna. No tocante às respostas dessa questão, percebe-se que novamente essa atividade é sempre executada por apenas $22 \%$ dos respondentes. Em sua maioria, $67 \%$, os respondentes regularmente praticam essa atribuição. Outros $11 \%$, novamente, informaram que nunca participam na elaboração dos relatórios supracitados. Observa-se, nessa situação, que em sua maioria os controladores atestam os índices expressos nos documentos sem a verificação do que está manifestado em tais relatórios. Em suma, propõese que não há realização de controle quanto a atestação das informações contidas nos demonstrativos analisados.

\section{CONSIDERAÇÕES FINAIS}

Ao longo da presente pesquisa, buscou-se descobrir as principais atribuições e as atividades que foram evidenciadas como maiores dificuldades dos controladores internos dos municípios da região da AMCESPAR, no estado do Paraná. Este estudo, caracterizado como de natureza descritiva, foi realizado mediante levantamento de dados aplicado por meio de um questionário estruturado, e utilizou-se de material bibliográfico e documental. O Controle Interno consagra-se como uma grande ferramenta da 
Administração Pública que visa amparar a qualidade da gestão. Suas atividades favorecem a apuração de irregularidades da entidade pública, como também, está à espreita da exigência de uma administração eficiente, eficaz e econômica. Esse proeminente órgão promove o atendimento aos princípios constitucionais e informa o gestor municipal sobre equívocos ocorridos na operacionalização dos processos internos da entidade.

O controle interno deve atuar de forma sistêmica, acoplando ações de governança e governabilidade visando a respaldar as decisões e realizações que tenham por escopo o bem comum, função precípua do Estado albergado no princípio de sua continuidade (BULIGON, 2012). Os resultados demonstram, no tocante às características funcionais de "Fiscalização" e de "Elaboração de Relatórios", que as atribuições que mais se destacaram foram a fiscalização e controle quanto às despesas realizadas nas áreas de Saúde, Educação e pessoal; e a apresentação periódica de informações obtidas pelas análises do Controle Interno ao gestor municipal. As atividades que mais demonstraram dificuldade em serem realizadas, por sua vez, foram evidenciadas como sendo: elaborar relatórios com o objetivo de validar índices obrigatórios; a fiscalização de convênios; a verificação da fidedignidade das prestações de contas de subvenções repassadas e a ausência de solicitação de parecer do controle interno, por parte dos responsáveis dos setores da Administração Pública, quando da deficiência de planejamento de dispêndios.

Em relação às características funcionais de "Planejamento e Execução Orçamentária" averiguou-se, que as atividades atributivas mais destacadas pelos controladores respondentes foram: o acompanhamento e fiscalização da adequação da LOA quanto ás diretrizes do PPA e a fiscalização de empenhos e pagamentos periodicamente. As maiores dificuldades evidenciadas em relação às referidas características estão relacionadas a solicitação de parecer do setor de $\mathrm{Cl}$ quando da verificação de recursos públicos para a execução de atividades e; quando do auxílio da elaboração das Leis Orçamentárias, e no controle e acompanhamento dessas leis.

No tocante às características funcionais de "Suporte para Correção de Erros" e "Prestação de Contas", verificou-se que as principais atividades atributivas exercidas periodicamente é a participação ativa em audiências públicas e a exposição de erros administrativos ao gestor, visando correções. Os impasses encontrados concentram-se na verificação do cumprimento das metas do PPA, objetivando a execução da gestão responsável; e no quesito do acompanhamento e participação no RREO e RGF; além da falta de apoio jurídico para subsidiar as decisões dos controladores; a carência de idealização prévia das atividades a serem realizadas pela Administração Pública; a ausência do estabelecimento de mecanismos que comprovem a gestão fiscal responsável, e a falta de integração entre os setores da Administração Pública. Tais situações possibilitam a ocorrência de falhas no processo administrativo da entidade pública.

Dessa forma, conclui-se que as atribuições mais executadas pelos controladores da amostra da pesquisa são: a participação efetiva em audiências públicas; a verificação periódica de empenhos emitidos e pagamentos efetuados; a averiguação dos índices obrigatórios; e o acompanhamento e fiscalização da adequação da LOA quanto às diretrizes do PPA. Evidenciaram-se, nesse estudo, as dificuldades a saber: falta de apoio jurídico para subsidiar as decisões dos controladores; a deficiência na estrutura de pessoal, a 
carência de idealização prévia das atividades a serem realizadas pela Administração Pública; a ausência do estabelecimento de mecanismos que comprovem a gestão fiscal responsável, e a falta de integração entre os setores da Administração Pública.

Ressalta-se que os resultados apresentados nesse estudo se limitam a amostra utilizada, bem como, os instrumentos empregados no processo de coleta e análise dos resultados. Sugere-se para futuras pesquisas o aumento da amostra investigada, assim como, a comparação com profissionais contábeis de outros estados brasileiros.

\section{REFERÊNCIAS}

AMUDO, A.; INANGA, E. L.. Evaluation of internal control systems: a case study from Uganda. International Research Journal of Finance and Economics, v.1, n.27, p.124-144, 2009.

ANDRADE, N. A. Contabilidade Pública na gestão municipal. 5 ed. São Paulo: Atlas, 2013.

BEUREN, I. M.. Como elaborar trabalhos monográficos em contabilidade. São Paulo: Atlas, 2012.

BEUREN, I. M.; ZONATTO, V. C. S.. Perfil dos artigos sobre controle interno no setor público em periódicos nacionais e internacionais. Revista de Administração Pública, v.48, n.5, p.1135-1163, 2014.

BOFF. M. L.; BEUREN, I. M.; GUERREIRO, R.. Institucionalização de Hábitos e Rotinas da controladoria em Empresas do estado de Santa Catarina. Revista

Organizações \& Sociedade, v.15, n.46, 2008.

\section{BORINELLI, M. L.. Estrutura conceitual básica da}

Controladoria: sistematização à luz da teoria e da práxis. Tese (Doutorado em Controladoria e Contabilidade) Universidade de São Paulo, São Paulo, 2006.

BRASIL. Constituição da República Federativa do Brasil de 1988. Brasília, 05 out. 1988.

BRASIL. Lei Complementar no 101, de 04 de maio de 2000. Estabelece normas de finanças públicas voltadas para a responsabilidade na gestão fiscal e dá outras providências. Brasília: DOU, 2000.

BROWN, N. C.; POTT, C; WÖMPENER, A. The Effect of Internal Control and Risk Management Regulation on Earnings Quality: Evidence from Germany. J. Account. Public Policy, v.33, p.1-31, 2014.

BULGARI, R.. Apostila: O Sistema de Controle Interno Curso Técnico. Curitiba: Unipública, 2014.

BULIGON, D. O controle interno na administração pública como instrumento de governança e governabilidade na gestão dos municípios paranaenses. Dissertação (Mestrado em Planejamento e Governança Pública) - Universidade Tecnológica Federal do Paraná, Curitiba, 2012.

CALLADO, A. L. C. As funções da controladoria no setor público: a percepção de quem faz a Controladoria Geral da
União. In: 13 Congresso USP: Controladoria e

Contabilidade. São Paulo, 2013.

CASTRO, D. P. Auditoria, contabilidade e controle interno no setor público: integração das áreas do ciclo de gestão: contabilidade, orçamento e auditoria e organização dos controles internos, como suporte à governança corporativa. 5 ed. São Paulo: Atlas, 2013.

CONSELHO FEDERAL DE CONTABILIDADE (CFC). Normas brasileiras de contabilidade: contabilidade aplicada ao setor público: NBCs T 16.1 a 16.11/ Conselho Federal de Contabilidade. -- Brasília: Conselho Federal de Contabilidade, 2008.

FRANCO, L. M.; BENNETT, S., KANFER, R. Health sector reform and public sector health worker motivation: a conceptual framework. Social Science \& Medicine, v.54, n.8, p.1255-1266, 2002

GADELHA, S. R. B. Análise dos Impactos da Lei de Responsabilidade Fiscal sobre a Despesa de Pessoal e a Receita Tributária nos Municípios Brasileiros: Um Estudo com Modelo Probit Aplicado a Dados em Painel. Brasília: STN, 2012.

GIL, A. C. Métodos e técnicas de pesquisa social. 5 ed. São Paulo: Atlas, 2007.

KOMINIS, G.; DUBAU, A. I. Time for interactive control systems in the public sector? The case of the Every Child Matters policy change in England. Management Accounting Research, v.23, n.2, p.142-155, 2012.

MARCONI, M. A.; LAKATOS, E. M.. Fundamentos de metodologia científica. São Paulo: Atlas, 2003.

MARTIN, K.; SANDERS, E.; SCALAN, G.. The Potential Impact of COSO Internal Control Integrated Framework Revision on Internal Audit Structured SOX Work Programs. Research in Accounting Regulation, v.26, p.110-117, 2014.

OLIVEIRA, S. L.. Tratado de Metodologia Científica. 2 ed. São Paulo: Pioneira, 1999.

PISCITELLI, R. B.; TIMBÓ, M. Z. F.. Contabilidade Pública: uma abordagem da administração financeira pública. 13 ed. São Paulo: Atlas, 2014.

QUINTANA, A. C.. Contabilidade Pública de acordo com as novas normas brasileiras de contabilidade aplicadas ao 
setor público e a Lei de Responsabilidade Fiscal. São Paulo: Atlas, 2011.

SCHMIDT, P.; SANTOS, J. L.; MARTINS, M. A. S.. Manual de Controladoria. São Paulo: Atlas, 2014.

SILVA JÚNIOR, S. D; COSTA, F. J.. Mensuração e Escalas de Verificação: uma Análise Comparativa das Escalas de Likert e Phrase Completion- Revista Brasileira de Pesquisas de Marketing, Opinião e Mídia. São Paulo, v.15, p.1-16, 2014.
SOUZA, D. C.; KUHL, M. R.; RIBEIRO, R. R. M.; CLEMENTE, A.. Controle Interno na Administração Pública: Uma amostragem da implantação no estado do Paraná. Revista Enfoque v. 26, n. 2, p. 29-39, 2007.

VICCARI JUNIOR, A.. Lei de responsabilidade fiscal comentada: lei complementar no 101, de 4 de maio de 2000 . 5 ed. São Paulo: Atlas, 2006. 